\title{
Macular grid laser photocoagulation in uveitis
}

\author{
M S A Suttorp-Schulten, E Feron, F Postema, A Kijlstra, A Rothova
}

\begin{abstract}
Aims/Background-The aim of this study was to evaluate whether grid laser photocoagulation of the macula is beneficial in the treatment of cystoid macular oedema in patients with uveitis.

Methods-Six eyes of five patients with long standing cystoid macular oedema due to chronic uveitis were treated by grid laser photocoagulation of the macula. Results-In the first weeks after treatment a temporary increase of oedema and paracentral scotomas were observed. At the long term follow up of more than 18 months in all patients, macular oedema had been reduced significantly or disappeared in all eyes treated. One eye had a significant increase in Snellen acuity, three eyes more or less stabilised, and two eyes deteriorated.

Conclusion-The beneficial effect of laser treatment on visual acuity in patients with uveitis might be more favourable if performed at an earlier stage of the disease.
\end{abstract}

(Br f Ophthalmol 1995; 79: 821-824)

Uveitis is an important cause of visual handicap and blindness in the Western world, accounting for about $10 \%$ of total blindness in the United States. ${ }^{1}$ It can often be treated effectively in its active phase by medication; many complications of uveitis can be controlled by surgery or by drugs - for example, cataract and glaucoma. ${ }^{2}$ The major cause of visual loss in chronic uveitis is cystoid macular oedema, which can persist despite aggressive treatment and resolution of active inflammation. Symptomatic treatment includes topical and systemic anti-inflammatory drugs - steroids as well as non-steroids - and oral acetazolamide. ${ }^{23}$ Hyperbaric oxygen and surgical therapy (vitrectomy) are still controversial. ${ }^{4-6}$

Non-uveitic causes of chronic cystoid macular oedema include diseases with a vascular pathogenesis - for example, diabetic maculopathy, branch vein and central vein occlusion, and surgical trauma - for example, aphakic cystoid macular oedema. It is generally accepted that grid laser photocoagulation of the macula can enhance the resolution of long standing oedema and improve visual outcome in cystoid macular oedema of vascular origin..$^{7-12}$ Whether laser treatment is also beneficial in the treatment of cystoid macular oedema in uveitis is not known and was the subject of this retrospective study. We treated six eyes in five patients with chronic uveitis and long standing cystoid macular oedema refractory to medication with grid laser photocoagulation and evaluated the effect on visual outcome.

\section{Materials and methods}

All patients were examined and screened for uveitis according to standard procedures described elsewhere. ${ }^{13}$ This included a complete ophthalmic examination, complete blood count, HLA-B 27, angiotensin converting enzyme, serology for syphilis, and chest radiography. Laser treatment was performed according to procedures as described for diabetes mellitus. ${ }^{8}$ The green argon laser was used with a $100-200 \mu \mathrm{m}$ spot size. Intensity started at $100 \mathrm{~mW}$ and increased until a very mild blanching of the retina was reached. Coagulations were placed approximately one burn width apart. Between 70 and 100 burns were used to form a grid that encircled the foveal avascular zone. Four patients (cases 1-4) were treated by the same ophthalmologist (FP).

In all cases cystoid macular oedema was documented before treatment with fluorescein angiography. The effects of laser treatment on the macula at long term follow up were also evaluated by fluorescein angiography.

\section{CASE REPORTS}

Case 1

A 51-year-old woman suffered from bilateral posterior uveitis with vitritis, periphlebitis, and cystoid macular oedema for 5 years when she was first seen at our clinic in 1991. Visual acuity was 0.5 in both eyes and no signs of active inflammation were seen, only some vitreous floaters and mild cystoid macular oedema. Uveitis screening disclosed no abnormalities. Despite treatment (see Table 1) visual acuity deteriorated to $0 \cdot 1$ right eye and 0.3 left eye; in both eyes symmetrical macular oedema was seen. The macula of the right eye was treated by grid laser photocoagulation. After 4 weeks the patient complained of paracentral scotomas and increase of metamorphopsia, accompanied by increase of oedema on funduscopy. Because the patient persistently complained of metamorphopsia and micropsia in her right eye, cyclosporin was added to the therapy 6 months after laser treatment. The visual acuity of the treated eye remained stable and fluctuated around $0 \cdot 1$ until last follow up at 21 months after treatment. The fluorescein angiography 8 months after laser treatment documented no leakage in the macula of the treated right eye and evident cystoid macula oedema in the untreated left eye. At last follow up, 21 months after treatment, the right eye still showed decreased cystoid macular oedema, both on ophthalmoscopy as on fluorescein angiography.

Case 2

A 35-year-old man was known to have biopsy
Research Institute,

12141, $1100 \mathrm{AC}$

Amsterdam, the

Accepted for publication 4 April 1995 
Figure 1 Late phase fluorescein angiogram of patient No 2 before treatment shows leakage consistent with cystoid macular oedema in both eyes $(A)$ right eye and $(B)$ left eye.

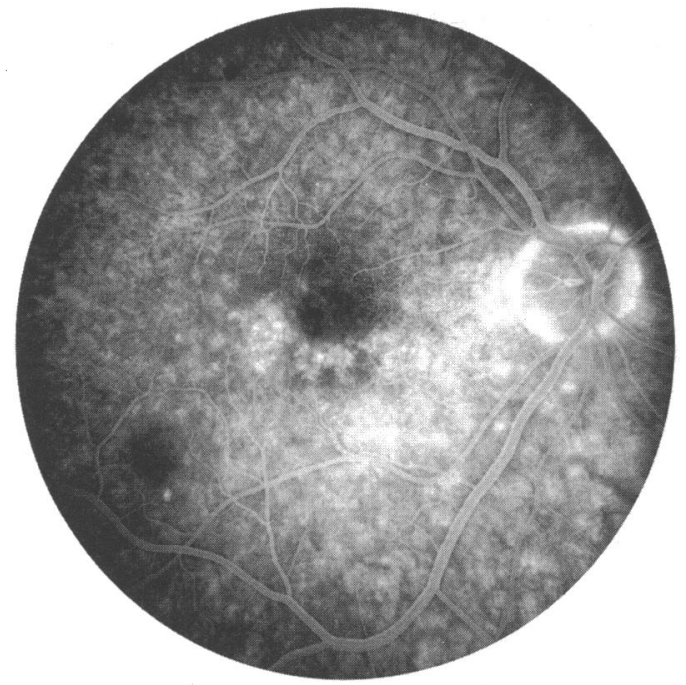

Fig $1 A$

proved sarcoidosis since 1981. In 1988 best corrected visual acuity was 0.8 right eye and $0 \cdot 2$ left eye and, except for bilateral cystoid macular oedema and low grade intermediate uveitis, no abnormalities were found. The results of uveitis screening were compatible with active sarcoidosis. The macular oedema initially responded to therapy (see Table 1) but in 1992 a severe recurrence in the left eye remained refractory to high doses of oral corticosteroids, as confirmed by fluorescein angiography (Fig 1). Best corrected visual acuity decreased to 0.5 right eye and 0.2 left eye; grid laser treatment was performed on the left eye. For several weeks after laser treatment the patient experienced annoying paracentral scotomas and a temporary increase of oedema which was treated by acetazolamide. Three months after laser treatment the oedema had resolved, which was confirmed by fluorescein angiography 6 months after the initial treatment (Fig 2). The paracentral scotomas gradually diminished within several months. Visual acuity at the last visit 18 months after therapy was 0.6 right eye and 0.2 in the treated left eye, which was still free of oedema at that time, as confirmed by fluorescein angiography.

\section{Case 3}

This 31-year-old man had suffered from a uveomeningeal syndrome with intermediate uveitis since 1985 . Despite routine screening for uveitis and extensive screening focused on neurosarcoidosis, multiple sclerosis, VogtKoyanagi-Harada syndrome, and Lyme disease, no underlying disease could be found. Cystoid macular oedema had reacted well to therapy initially (see Table 1). At the beginning of 1992 cataract surgery on the right eye resulted in an improvement of visual acuity to 0.6 . In the left eye it had dropped to 0.3 caused by fulminant cystoid macular oedema which was refractory to oral corticosteroids. Fluorescein angiography confirmed the presence of cystoid macular oedema bilaterally and grid laser therapy of the left eye was undertaken. Three months later an increase

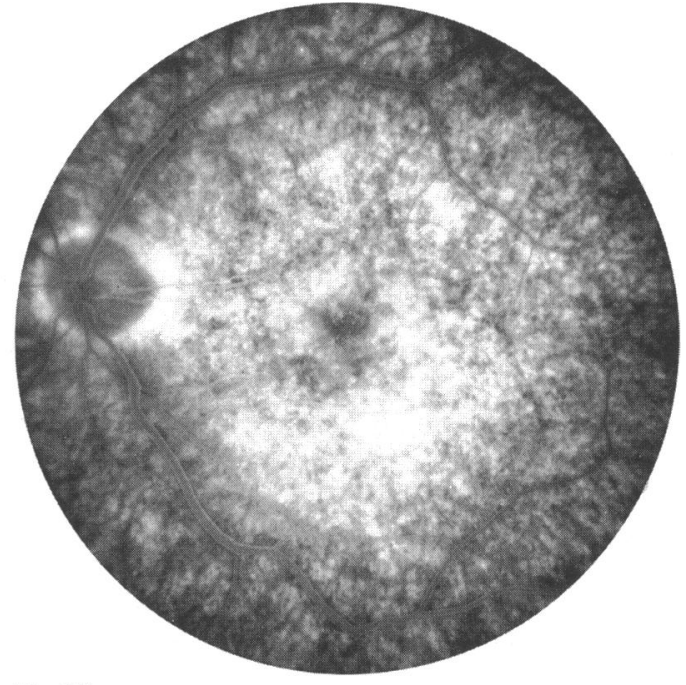

Fig $1 B$

in the oedema was noted and the patient complained about paracentral scotomas. Cataract also developed in this eye; surgery was performed in October 1992 with increase in visual acuity to $0 \cdot 8$. Cystoid macular oedema gradually decreased in the left eye, compared with the right, untreated eye. At the beginning of 1994 the patient received high doses of steroids for several weeks because of his meningitis. Visual acuity was 0.5 right eye and 0.8 left eye at the last visit 24 months after the laser treatment and on fluorescein angiography cystoid macular oedema in the left treated eye had resolved but persisted in the fellow eye.

\section{Case 4}

A 61-year-old woman was first seen in 1988 with a bilateral posterior uveitis, associated with a biopsy proved pulmonary sarcoidosis. In the same year she developed a non-insulin dependent diabetes mellitus. Visual acuity was 0.3 right eye and 0.2 left eye. Significant bilateral macular oedema was already present at the first visit. Fluorescein angiography disclosed cystoid macular oedema, but no signs of diabetic retinopathy. Local treatment with subconjunctival corticosteroids did have some effect, as visual acuity increased by one line of Snellen acuity, but the patient developed secondary glaucoma and cataract. In 1989 both eyes underwent cataract and glaucoma surgery. Visual acuity stabilised at 0.8 right eye, but decreased to 0.2 left eye. Both eyes had persistent macular oedema, the left eye more than the right, as shown by fluorescence angiography. Oral prednisone was not given because of possible complications of the diabetes mellitus. In September 1992 a laser grid was placed in the left macula. At the short term follow up the patient did not have any complaints and visual acuity remained stable. One and a half years later, visual acuity was 0.5 right eye and $0 \cdot 2$ left eye and there was still considerable cystoid macular oedema in the right eye, but a significant decrease in the left treated eye. This was confirmed by fluorescein angiography. 


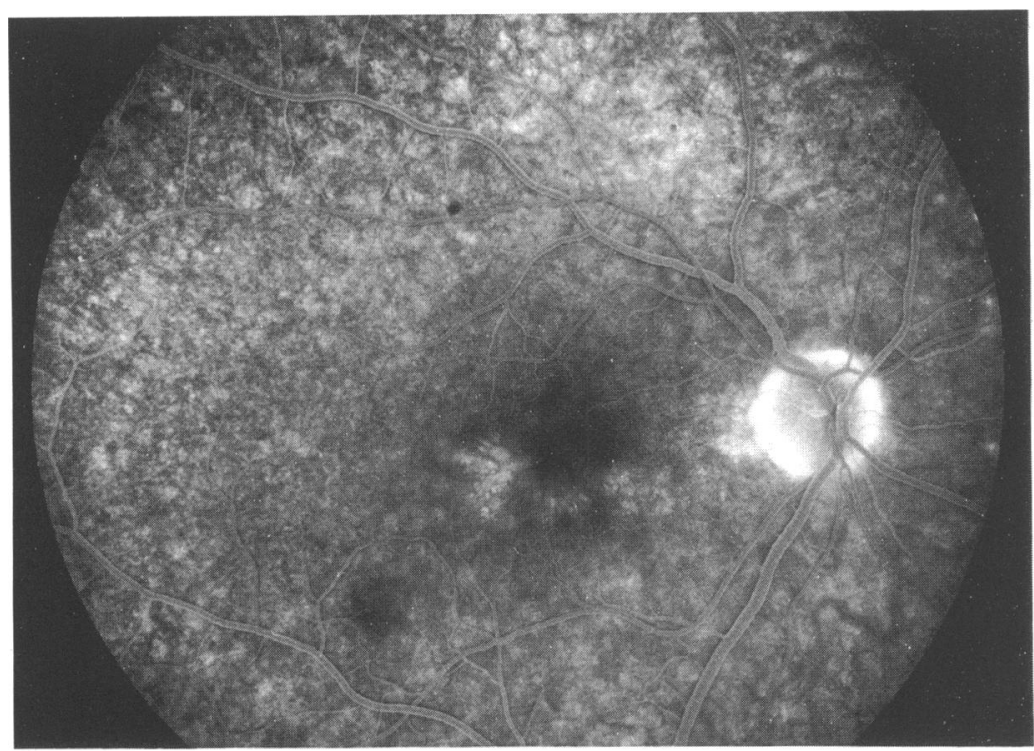

Fig $2 A$

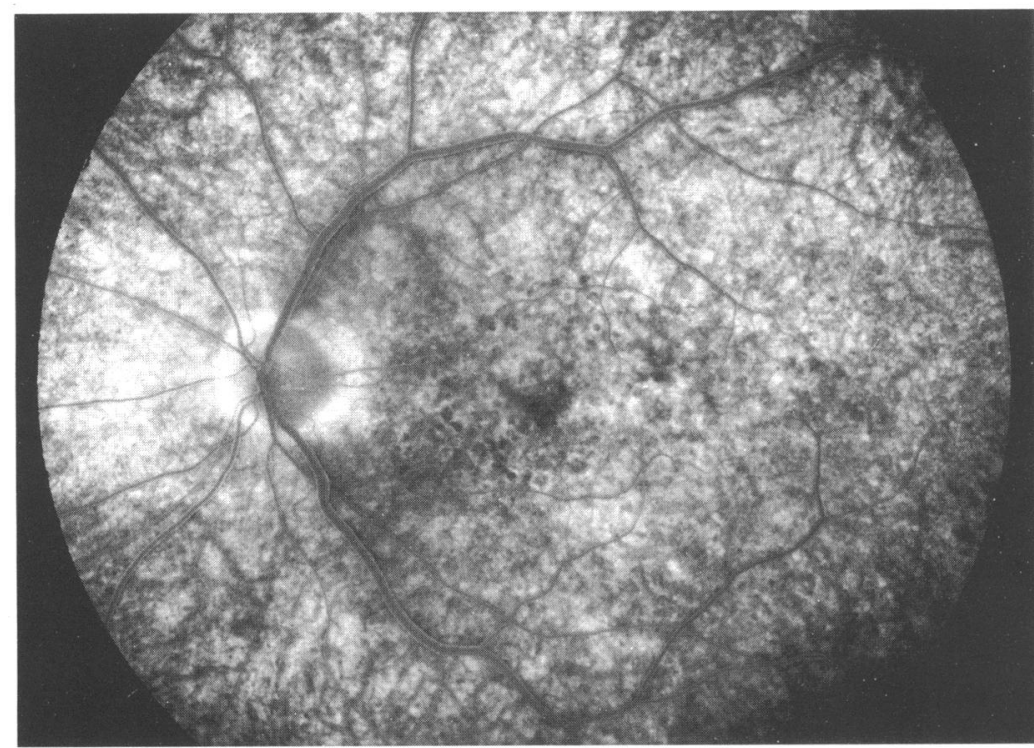

Fig $2 B$

Figure 2 Late phase fluorescein angiogram of patient No 23 months after treatment shows persisting macular oedema in the right eye $(A)$, and no more leakage in the left treated eye $(B)$

Case 5

This 55-year-old woman was diagnosed with an HLA-A 29 positive birdshot chorioretinopathy in 1985. Despite systemic treatment (see Table 1) visual acuity decreased to 0.2 right eye and 0.1 left eye in 1990 because of symmetrical bilateral massive cystoid macular oedema. This was confirmed by extensive leakage on fluorescein angiography. Both eyes underwent grid photocoagulation of the macula, the right eye in December 1990 and the left eye in May 1991. Shortly after treatment no subjective complaints developed. Despite further treatment with cyclosporin and oral acetazolamide, visual acuity decreased to $0 \cdot 1$ right eye and finger counting at 3 metres in the left eye. Fluorescein angiography was repeated in December 1993, up to 3 years after she underwent laser treatment and showed absence of leakage from the macula in both treated eyes.

\section{Results}

All six of the treated eyes in five patients showed disappearance or a considerable decrease in cystoid macular oedema at long term follow up. Three patients (Nos 1, 2, 3) developed a temporary increase of macular oedema within the first weeks after treatment. Furthermore, these three patients complained of increases in metamorphopsia and paracentral scotomas in this same period. The patients were all followed for more than 18 months, with a mean follow up of 26 months. The effects of the treatment on cystoid macular oedema and visual acuity are shown in Table 1 and Figure 3. In all six eyes treated the reduction of cystoid macular oedema was confirmed by fluorescein angiography. In four patients (Nos 1, 2, 3, 4) with bilateral cystoid macular oedema only one eye was treated and the natural course of the disease on the fellow eye could be used as a control. In these four patients cystoid macular oedema persisted in the untreated eye.

Visual acuity remained unchanged in two treated eyes (Nos 1,4$)$, improved in two eyes by one and five lines of Snellen acuity, respectively (Nos 2, 3), and decreased by one line of Snellen acuity in two eyes (both eyes of patient No 5). In comparison, the visual acuity of the four untreated fellow eyes improved one line in one eye (No 2), decreased one line in two eyes (Nos 1, 3), and decreased three lines of Snellen acuity in one eye (No 4).

\section{Discussion}

Chronic cystoid macular oedema is one of the most serious complications in uveitis. It causes structural changes in the anatomy of the

Table 1 Patient characteristics and treatment

\begin{tabular}{|c|c|c|c|c|c|c|c|}
\hline $\begin{array}{l}\text { Case no, } \\
\text { age (years), } \\
\text { sex,eye treated }\end{array}$ & $\begin{array}{l}\text { Duration } \\
\text { cystoid macular } \\
\text { oedema (years) }\end{array}$ & Previous treatment & $\begin{array}{l}\text { Laser } \\
\text { inferometry }\end{array}$ & $\begin{array}{l}\text { Visual } \\
\text { acuity before } \\
\text { treatment }\end{array}$ & $\begin{array}{l}\text { Paracentral } \\
\text { scotomas } 3 \text { months } \\
\text { after therapy }\end{array}$ & $\begin{array}{l}\text { Duration of } \\
\text { follow up } \\
\text { (months) }\end{array}$ & $\begin{array}{l}\text { Visual acuity } \\
\text { and cystoid macular } \\
\text { oedema at last follow up }\end{array}$ \\
\hline $1,52, F, R E$ & 6 & $\begin{array}{l}\text { Topical indomethacine, dexamethasone } \\
\text { Parabulbar triamcinolone } \\
\text { Systemic acetozolamide, corticosteroids }\end{array}$ & $\mathrm{CF}$ & $0 \cdot 1$ & Yes & 21 & 0.1 decreased \\
\hline $2,38, M, L E$ & 6 & $\begin{array}{l}\text { Topical indomethacine, dexamethasone } \\
\text { Parabulbar triamcinolone } \\
\text { Systemic acetozolamide, corticosteroids }\end{array}$ & 0.3 & $0 \cdot 1$ & Yes & 18 & 0.2 disappeared \\
\hline 3, 46, M, LE & 7 & $\begin{array}{l}\text { Topical indomethacine, dexamethasone } \\
\text { Parabulbar triamcinolone } \\
\text { Systemic acetozolamide, corticosteroids }\end{array}$ & 0.4 & 0.3 & Yes & 24 & 0.8 disappeared \\
\hline $4,63, F, L E$ & 4 & $\begin{array}{l}\text { Topical dexamethosone } \\
\text { Parabulbar triamcinolone }\end{array}$ & Not done & $0 \cdot 2$ & No & 18 & 0.2 decreased \\
\hline $\begin{array}{l}\text { 5, 60, F, RE } \\
\text { 5, 60, F, LE }\end{array}$ & $\begin{array}{l}8 \\
8\end{array}$ & $\begin{array}{l}\text { Systemic corticosteroids, cyclosporin } \\
\text { Systemic corticosteroids, cyclosporin }\end{array}$ & $\begin{array}{l}\text { Not done } \\
\text { Not done }\end{array}$ & $\begin{array}{l}0 \cdot 2 \\
0 \cdot 1\end{array}$ & $\begin{array}{l}\text { No } \\
\text { No }\end{array}$ & $\begin{array}{l}36 \\
31\end{array}$ & $\begin{array}{l}0 \cdot 1 \text { disappeared } \\
\text { CF disappeared }\end{array}$ \\
\hline
\end{tabular}




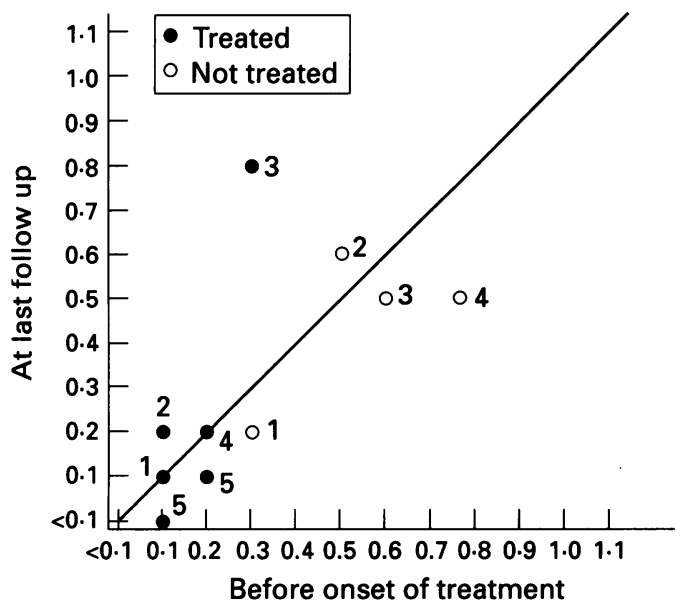

Figure 3 Visual acuities of six eyes in five patients before and after treatment. Numbers indicate patient number in text.

macula and thereby may lead to irreversible impairment of visual function. It is mainly seen in intermediate uveitis, but can also complicate any other form of uveitis. ${ }^{14}$ Treatment of active intraocular inflammation with topical, periocular, or systemic immunosuppressive therapy often results in regression of cystoid macular oedema. ${ }^{15}$ Unfortunately, in some patients it persists even after the activity of the underlying inflammation is completely under control.

In the past decade laser techniques have been shown to have a beneficial effect in patients with cystoid macular oedema secondary to retinal vascular disease. According to the Retinal Branch Vein Occlusion Study, macular oedema persisting for longer than 6 months had a better visual prognosis if treated by argon laser coagulation. In this study, the visual acuity was improved by two lines of Snellen acuity in most treated eyes. ${ }^{11}$ Patients suffering from cystoid macular oedema due to retinal central vein occlusion also benefit from grid laser photocoagulation as oedema resolves and visual acuity may improve. ${ }^{12} 16$ Similar results have been reported for macular oedema complicating diabetic maculopathy. ${ }^{7-9}$

In our patients, only one treated eye had a significant increase in Snellen acuity (No 3), three eyes more or less stabilised (Nos 1, 2, 4), and two eyes deteriorated (No 5 both eyes). Oedema temporarily increased during the first weeks after treatment, but significantly decreased or disappeared in all patients at long term follow up. This effect was stable during the whole period of follow up, which was more than 18 months in all cases. Our findings are in only a small group of patients with late stage macular oedema and are therefore difficult to interpret. The reduction of macular oedema as illustrated by fluorescein angiography would suggest that the potential for visual recovery in these eyes was low and that any therapy might prove equally ineffective in improving vision. The complaints of paracentral scotomas (three out of five patients - in the two unaffected cases, one had associated diabetes mellitus and the other suffered from birdshot chorioretinopathy) are not usually encountered after grid treatment in patients with diabetes mellitus. This phenomenon might indicate that the condition of the retinal pigment epithelium and, therefore, the consequences of laser treatment in uveitis are different from those in patients suffering from diabetes mellitus.

The beneficial visual response in one patient with a better pretreatment acuity suggests that the results of laser treatment in patients with uveitis might be more favourable if performed at an earlier stage of the disease. Our results confirm an earlier study, showing that the mere existence of cystoid macular oedema does not cause the decrease in visual acuity but other factors, such as the duration of cystoid oedema, may play a role in the visual outcome. ${ }^{17}$ As macular oedema persists, fluid accumulation in Müller cells and the formation of macular cysts may lead to irreversible damage of macular, and thereby visual, function. 1819 The question arises whether the grid treatment should be instituted earlier, but since eyes with better visual potential were not included, the present study does not provide the answer. Further studies are needed to clarify this question and demonstrate whether the early laser treatment of cystoid macula oedema might reduce the serious visual handicap in patients with uveitis.

1 Nussenblatt RB. The natural course of uveitis. Int Ophthalmol 1990; 14: 303-8.

2 Dick AD. The treatment of chronic uveitic macular oedema. Br f Ophthalmol 1994; 78: 1-2.

3 Farber MD, Lam S, Tessler HH, Jennings ThJ, Cross A, Rusin MM. Reduction of macular oedema by acetazolamide in patients with chronic iridocyclitis: a randomised prospective crossover study. $\mathrm{Br}$ f Ophthalmol 1994; 78: 4-7.

4 Miyake Y, Awaya S, Takahashi H, Tomita N, Hirano $\mathrm{K}$. Hyperbaric oxygen and acetazolamide improve visual acuity in patients with cystoid macular edema by different mechanisms. Arch Ophthalmol 1993; 111: 1605 .

5 Dugel PU, Rao NA, Ozler S, Ligget PE, Smith RE. Pars plana vitrectomy for intraocular inflammation related cystoid macular edema unresponsive to corticosteroids. A preliminary study. Ophthalmology 1992; 99: 1535-41.

6 Heiligenhaus A, Bornfeld N, Foerster MH, Wessing A Long term results of pars plana vitrectomy in the management of complicated uveitis. Br $\mathcal{f}$ Ophthalmol 1994; 78: 549-54.

7 Early Treatment Diabetic Retinopathy Study Research Group. Photocoagulation for diabetic macular edema: early treatment diabetic retinopathy study report number early treatment diabetic retinopathy study

8 Early Treatment Diabetic Retinopathy Study Research Group. Early photocoagulation for diabetic retinopathy. ETDRS report number 9. Ophthalmology 1991; 98: 766-85.

9 Lee CM, Olk RJ. Modified grid laser photocoagulation for diffuse diabetic macular edema, long term visual results. Ophthalmology 1991; 98: 1594-602.

10 Krill AE, Archer D, Newell FW. Photocoagulation in complications secondary to branch vein occlusion. Arch Ophthalmol 1971; 85: 48-60.

11 The Branch Vein Occlusion Study Group. Argon laser photocoagulation for macular edema in branch vein photocoagulation for macular edema in br
occlusion. Am $\mathcal{f}$ Ophthalmol 1984; 98: 271-82.

12 Klein ML, Finkelstein D. Macular grid photocoagulation for macular edema in central retinal vein occlusion. Arch Ophthalmol 1989; 107: 1297-302.

13 Rothova A, Buitenhuis HJ, Meenken C, Brinkman CJJ, Linssen A, Alberts C, Luyendijk L, Kijlstra A. Uveitis and systemic disease. Br f Ophthalmol 1992; 76: 137-41.

14 Malinowski SM, Folk JC, Pulido JS. Pars planitis. Curr Opin Ophthalmol 1994; 5: 72-82.

15 Guex-Crosier Y, Othenin-Girard P, Herbort CP. Traitement differencie de l'oedeme maculaire cystoide inflammatoire postoperatoire et secondaire aux uveites. Klin Monatsbl Augenheilkd 1992; 200: 367-73.

16 Campbell JC, Wise GN. Photocoagulation therapy of branch vein obstructions. Am $\mathcal{f}$ Ophthalmol 1973; 75: branch

17 Nussenblatt RB, Kaufman SC, Palestine AG, Davis MD, Ferris FL. Macular thickening and visual acuity, measurement in patients with cystoid macular edema. Ophthalmology 1987; 94: 1134-9.

18 Fine BS, Brucker AJ. Macular edema and cystoid macular edema. Am $\mathcal{F}$ Ophthalmol 1981; 92: 466-81.

19 Tso MOM. Pathology of cystoid macular edema. Ophthalmology 1982; 89: 902-15. 